estimate of immobilization; but it was the best available in elderly patients usually incapable of giving a satisfactory account of their activity prior to admission.

\section{Discussion and Summary}

The results demonstrate that there is a tendency to approximation of the thoracic cage and pelvis with increasing age. The most important factor involved is an increased obliquity of the ribs, which is, at least in part, secondary to the development of senile kyphosis. Radiological evidence of senile osteoporosis is more likely to be found in individuals in whom this change is greater than the average. The explanation may be that osteoporotic shortening of the spine is a further factor in causing this approximation, but, alternatively, it is possible that the rather asthenic type of elderly individual, in whom obliquity of the ribs is above the average, is constitutionally more liable to develop senile osteoporosis.

Senile osteoporosis of the spine is shown to be very common in elderly chronic invalids; indeed, some degree of osteoporosis is almost universal. As in so many other medical conditions, however, it is impossible to define any sharp boundary between the normal ageing process in the spine and pathological osteoporotic change. There is a gradual and continuous variation between spines which, at one extreme, can be regarded as normal for the age group, and those at the other extreme which show severe unequivocal pathological osteoporosis.

From a practical clinical point of view, it can be stated that there is a fair likelihood that spinal osteoporosis of significant degree will be found in elderly individuals in whom the distance between the subcostal and suprailiac lines is less than $1 \%$ of the patient's height, corresponding in most cases to a distance of $\frac{1}{2}$ in. $(1.3 \mathrm{~cm}$.) or less.

We are indebted to Mr. K. Bray for carrying out the radiography and to Miss Perry for the clinical photograph.

\section{REFERENCES}

Brown, F. R., and Smith, G. (1945). Lancet, 1, 10.

Cunningham J (1893) J. Anat. Physiol. $27,257$.

Fairbank, T. (1951). An Atlas of General Affections of the Skeleton. Livingstone, Edinburgh and London.

Gray, H. (1949). Anatomy, Descriptive and Applied, 30th ed. Longmans, Green \& Co., London.

Lachmann, E., and Whelan, M. (1930, Radiology, 26, 165.

Powys, A. O. (1901). Biometrika, 1, 30.

Roberts, C. (1878). A Manual of Anthropometry. Churchill, London.

Snedecor, G. W. (1946). Statistical Methods, 4th ed. Iowa State College Press, Ames, U.S.A.

The third annual report of the British Empire Society for the Blind was published last week. Preliminary surveys have shown that more than a million people in the Colonies are blind, millions more have incapacitating eye diseases, and facilities are gravely inadequate. Most probably, according to the report, three-quarters of this blindness is preventable. The report describes the start of a systematic attack on "river blindness" (a variety of filariasis affecting the eyes) in West Africa. The disease is spread by a simulium fly. At least 100,000 people in the northern Gold Coast are victims of the disease, which in the past has depopulated whole villages. The Society has sent two teams, one medical under Dr. F. Rodger, an ophthalmologist, and the other composed of entomologists, to survey the problem in the Gold Coast, the Cameroons, and Northern Nigeria. One of the objects of the survey is to obtain exact information on the life history of the vector fly. In East Africa, where conditions are rather easier, treatment of the rivers with insecticides has been followed by a notable reduction in river blindness. Trachoma is another very important cause of blindness, and a pilot survey at Aden last year showed that in some villages everyone had it in some form or another.

\section{ACTINOMYCOSIS IN SCOTLAND}

BY

\section{A. PORTER, M.B., Ch.B.}

(From the Departments of Bacteriology, University of Aberdeen and Medical School, King's College, University of Durham)

Since 1891, when Wolff and Israel first isolated the causative organism of actinomycosis, Actinomyces israeli, much has been written on many aspects of this disease, but the literature reveals little information regarding its incidence. It is not surprising, therefore, to find in one textbook the statement that it is "not a common disease" (Topley and Wilson, 1946), and in another that it is " not infrequent" (Christian, 1947).

Most people will agree with Cope (1949) that "we must put aside the traditional and popular fairy-tale about infection from grass and straw," since from these sources aerobic actinomycetes only have been isolated. It is now commonly held that the infection is endogenous, arising from the micro-aerophilic actinomycetes found in the human mouth, which resemble closely the pathogenic Actinomyces israeli. Associated with the exogenous theory of infection was the suspicion that agricultural workers were more often the victims of this disease than those in non-agricultural occupations. Although our ideas regarding the origin of the infection may have changed, it does not necessarily follow that our views concerning the occupational incidence of the disease must also alter. The question of whether agricultural workers are in fact more prone to actinomycosis than others has not so far been satisfactorily answered. Before it can be it is necessary to relate the number of cases of the disease occurring in agricultural and non-agricultural workers to the total number of individuals at risk in the two groups in the area under consideration. A survey of actinomycosis in the northeast of Scotland in which particular attention was paid to this point has already been recorded (Porter, 1951). In view of the fact that the north-east of Scotland is predominantly agricultural it has seemed desirable to extend this survey to the rest of Scotland, in which there is a large industrial belt in addition to agricultural areas.

\section{Investigation}

The extended survey was designed to cover all cases of actinomycosis admitted to hospital for treatment during the thirteen years from 1936 to 1948 in those parts of Scotland not originally reported upon-that is, in the whole of the country excluding the five counties in the north-east. Information was sought from all general hospitals and from $x$-ray therapy departments. Not all the hospitals were able to provide the desired information, sometimes because of inadequate case records and sometimes on account of the absence of comprehensive filing systems covering the period under review.

It is recognized that a number of patients with actinomycosis in its less acute forms may have been treated at home by their own physicians and received no hospital treatment. Such are not included in the survey, and no systematic search of the records of the out-patient departments of the various hospitals was attempted. A few out-patient cases of the disease which had been referred to $x$-ray therapy departments for treatment were obtained from the records of these departments, and these have been included.

Any case lacking bacteriological or pathological confirmation of the clinical diagnosis has been excluded; likewise, a few cases whose normal residence was not in Scotland. 


\section{Results}

The results of this investigation have been combined with those of the previous survey of the north-east area in order to give an overall survey of actinomycosis in Scotland. Where necessary, figures for each of the surveys are given separately so that they may be compared.

The total number of cases for the whole of Scotland was 186, of which 98 came from the north-east area and the remaining 88 from the rest of Scotland. In view of the fact that at the 1931 Census the population of the five north- ${ }^{-}$ east counties (Aberdeen, Kincardine, Banff, Moray, and Nairn) was 444,000 , compared with $4,398,000$ for the rest of Scotland, it is surprising that the north-east area should account for more than half the total number of cases recorded. Even if allowance is made for the fact that $15.8 \%$ of the hospital beds in the rest of Scotland were not covered, there would still appear to be a disproportionately large number of cases from the north-east area.

\section{Location}

In a report from the Netherlands, van der Hoeden (1939) stated that actinomycosis was ten times as common in rural districts as it was in large towns. The 186 cases of actinomycosis in this survey were grouped according to whether these patients lived in large towns or not. Thirteen cases had occurred in members of the armed Forces, and, owing to the uncertainty of their location prior to admission to hospital they have been excluded, leaving 173 cases for consideration. The results show that there was no significant difference in the rate of attack between those resident in the large towns and those in the small towns and rural districts in the north-east area. However, when the rest of Scotland is considered it appears that there is a significant difference between the attack rate among residents of large towns and that among residents in smaller towns and rural districts: the disease is more prevalent in the latter group.

\section{Age Incidence and Sex}

The ages of 184 of the 186 cases are known, and their distribution in the various age groups is shown in the Chart. The maximum number of cases occurred in the 20-29 age

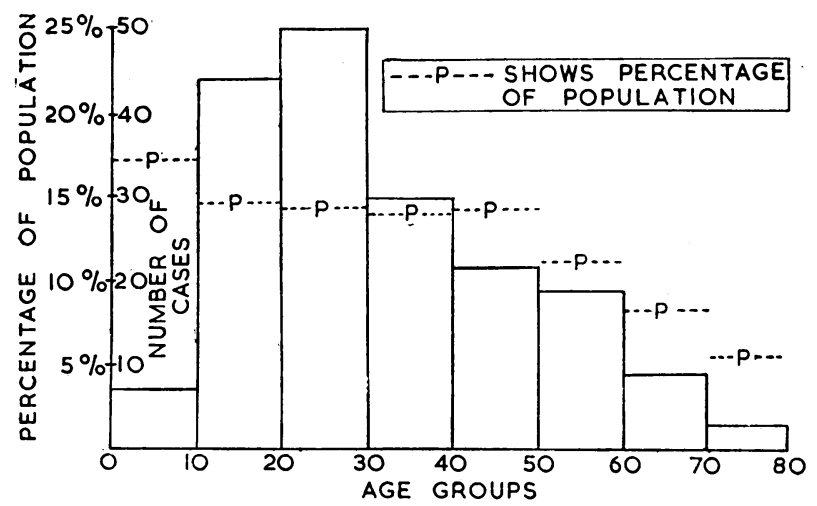

Chart showing distribution of 184 cases in age groups.

group. The combined number of cases in the 10-19 and 20-29 age groups is 94-just over half the total number. The percentage of the population in each age group is marked on the chart, and it can be seen that in the 10-19 and 20-29 age groups more cases of actinomycosis have occurred than would have been expected from the numbers of the population in these age groups.

Males are more commonly affected than females, as borne out by the fact that of the 186 cases $145(78 \%)$ were males.

\section{Anatomical Distribution and Incidence of Trauma}

The cervico-facial region is the most commonly affected portion of the body (65\%), followed by the abdominal region, which accounted for $19 \%$ of the infections. Actinomycosis of the cervico-facial region had occurred after dental extractions on 22 occasions, and in a further 33 patients in whom carious teeth had been noted. There was a history of injury to the face in 5 cases. In 23 of the abdominal cases there was a history of an associated appendicectomy, and in 2 cases of an appendix abscess. It is commonly agreed that actinomycosis may follow or be associated with appendicitis. Two cases of abdominal actinomycosis followed gastric perforations, and in 3 cases a blow to the chest or abdomen had preceded the onset of the disease.

\section{Occupational Incidence}

The occupations of 173 of the 186 cases are known. The occupation which accounted for the largest number of cases was agriculture, which gave a total of 39 , two of which were under 16 years of age. Since opinion in the past has been divided on the question of whether agricultural workers are more liable to this disease than those in non-agricultural occupations, it was thought desirable to submit the figures resulting from this survey to statistical analysis. The numbers of those engaged in agriculture and in non-agricultural occupations in Scotland between 1936 and 1948 were obtained through the courtesy of the Ministry of Labour. Only males between the ages of 18 and 64, of which there were 88 , were subjected to this analysis. The probability was calculated, and showed that, in Scotland, males between the ages of 18 and 64 engaged in agriculture were more liable to develop actinomycosis than those in non-agricultural occupations. The attack rate for male agricultural and non-agricultural workers in the two areas of Scotland are given in the accompanying Table.

Table Showing Attack Rate of Actinomycosis in Scotland of Male Workers

\begin{tabular}{|c|c|c|c|c|c|c|}
\hline & \multicolumn{2}{|c|}{ North-east Area } & \multicolumn{2}{|c|}{ Rest of Scot'and } & \multicolumn{2}{|c|}{ Total } \\
\hline & $\frac{\mathrm{Ca} \text { es }}{\mathrm{O} \cdot \mathrm{M} .}$ & $\begin{array}{c}\text { Ratio } \\
\text { per } \\
100,000\end{array}$ & $\frac{\text { Cases }}{\text { O.M. }}$ & $\begin{array}{c}\text { Ratio } \\
\text { per } \\
100,000\end{array}$ & $\frac{\text { Cases }}{\text { O.M. }}$ & $\begin{array}{c}\text { Ratio } \\
\text { per } \\
100,000\end{array}$ \\
\hline $\begin{array}{l}\text { Agricultural } \\
\text { workers }\end{array}$ & $\frac{19}{13,000}$ & 146 & $\frac{18}{62,000}$ & 29 & $\frac{37}{75,000}$ & 50 \\
\hline $\begin{array}{l}\text { Non-agricultural } \\
\text { workers }\end{array}$ & $\frac{20}{61,000}$ & 33 & $\frac{31}{919,0000}$ & $3 \cdot 3$ & $\frac{51}{980,000}$ & $5 \cdot 2$ \\
\hline
\end{tabular}

\section{Discussion}

Our knowledge of actinomycosis has increased greatly during the last 60 years, but there are still many questions to which answers are required. The theory of endogenous infection is now accepted by most workers in this field. Actinomyces israeli has been isolated, in the absence of clinical actinomycosis, from carious cavities, from periodontal abscesses, from dental deposits, and from tonsils. Its existence in the mouth offers a possible explanation of the frequency with which the cervico-facial region and the gastro-intestinal tract are affected. It would appear from investigations concerned with the isolation of microaerophilic actinomycetes from the mouth that these organisms have been recovered in only some $5 \%$ of instances. Thus Lord and Trevett (1936) isolated four strains of anaerobic actinomycetes from dental scum and carious teeth of 90 patients, while Sullivan and Goldsworthy (1940) isolated five strains of anaerobic actinomycetes from 100 periodontal abscesses and one strain from 24 carious teeth. However, Emmons (1937) isolated micro-aerophilic actinomycetes in $23 \%$ of cultures from 100 pairs of tonsils.

No details are given of the sex and age of the patients mentioned in these investigations. In view of the fact that this disease is more common in males and in those in certain age groups, it would be of much interest to know if microaerophilic actinomycetes are present more often in male than in female mouths, and in certain age groups more often than in others; also if mouths of agricultural workers and rural residents harbour this organism more commonly 
than mouths of non-agricultural workers and residents of the larger towns. Such information might be helpful in revealing factors which have so far not been taken into account in working out the epidemiology of this disease.

Although it has been found that male agricultural workers are more liable to actinomycosis than male workers in nonagricultural occupations it does not mean that we must connect this disease with the aerobic actinomycetes found in grains or grasses or even with the presence of the anaerobic Actinomyces bovis of lumpy jaw in cattle. Erikson (1940), made a detailed study of 20 strains of micro-aerophilic actinomycetes, 15 of which were of human origin and 5 of bovine origin. She showed that there were certain morphological, physiological, and serological differences between the human and bovine strains. Slack et al. (1951), however, in an examination of 11 human strains and 5 bovine strains isolated from cases of actinomycosis showed that they were serologically related. There is little information available concerning the frequency of actinomycosis in cattle and no evidence as yet to warrant connecting bovine with human cases of the disease. The lack of knowledge of the epidemiology of the disease in cattle would appear to be as great as it is in the case of the human subject.

\section{Summary}

A survey of the occurrence of actinomycosis in Scotland during the 13 years from 1936 to 1948 revealed 186 cases. All had bacteriological or pathological confirmation of the clinical diagnosis.

The commonest site of infection was the cervico-facial region, and males were more often affected than females.

Male agricultural workers were found to be more liable to this disease than those in other occupations. There was no significant difference in the attack rate of the residents of the larger towns and rural areas in the north-east of Scotland, but the residents of the larger towns in the rest of Scotland were found to be much less frequently the subjects of this disease than those living in essentially rural areas.

I wish to thank the medical superintendents of the various hospitals in Scotland and their records staff for help in obtaining the information on which this paper is based. For advice and assistance on statistics I am grateful to Mr. H. Campbell, Nuffield Department of Industrial Health, King's College, Newcastle-uponTyne.

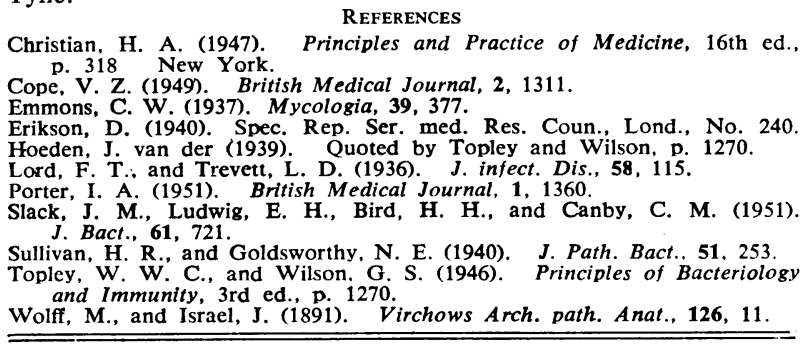

The City Council of Nottingham has recently published an attractive handbook describing the facilities available in the city for users of the National Health Service. The book opens with a brief summary of the medical services during the last hundred years up till 1948. It then describes in simple terms what maternal and child welfare facilities there are in Nottingham, and gives a detailed account of the work of the health visitors, midwives, district nurses, and home helps., In a chapter entitled "Care Service" the book tells of the services for the prevention of illness, by immunization and vaccination, and the control of the spread of tuberculosis and other infectious diseases. There is also a short description of the sanitary services and of the council's efforts to promote smoke abatement and slum clearance. The handbook concludes with the addresses of hospitals and clinics in and around Nottingham where different kinds of treatment may be obtained.

\section{SPECIFIC BACTERIOLYSIN IN SUBACUTE BACTERIAL ENDOCARDITIS CAUSED BY A HAEMOLYTIC STAPHYLOCOCCUS ALBUS}

\author{
BY
}

MARGARET M. O'HARE, F.R.F.P.S., M.R.C.P. Assistant Physician, Southern General Hospital, Glasgow AND

JOHN S. STEVENSON, M.D.

Assistant Pathologist, Stobhill General Hospital, Glasgow

This report records a case of subacute bacterial endocarditis (S.B.E.) in which there was serological evidence that the causal organism was a haemolytic coagulasenegative strain of Staphylococcus albus. So far as can be ascertained, serological evidence of infection in S.B.E. has not been recorded previously. The particular interest in this case was the presence of a specific bacteriolysin in the serum.

Between 1945 and 1952 British and American literature recorded over 30 cases of S.B.E. due to coagulasenegative white staphylococci, and it has been suggested (Dowling et al., 1952) that this type of endocarditis may be increasing in frequency. Out of a total of 2,100 cases of S.B.E. reported in five reviews (Thayer, 1931 ; Perry, 1936 ; White et al., 1945 ; Priest et al., 1947 ; Cates and Christie, 1951), Staph. albus was the causal organism in 20 instances - that is, about $1 \%$. Individual cases are reported from time to time (for example, Cunliffe et al., 1943 ; Matthew, 1951 ; Cobb, 1952), and serve to emphasize the fact that Staph. albus should not be regarded invariably as a contaminant when found in the blood cultures from these cases.

\section{Case Report}

The patient, a married woman aged 33, had a long "rheumatic" history, having had three attacks of acute rheumatism at 14, 27, and 29 years. Between 1947 and 1950 she was admitted to hospital on four occasions, suffering from various degrees of cardiac failure, with mitral stenosis and fibrillation. In 1947 and 1948 she was in hospital for some weeks; rapid improvement was brought about with rest and digoxin therapy.

On April 13, 1949, she was admitted to hospital for the third time, again with severe fibrillation; as before, this was treated with digoxin. Improvement was rapid, but on May 9 it was found that the spleen was enlarged to one and a half fingerbreadths below the costal margin. A persistent anaemia ( $\mathrm{Hb}, 7 \mathrm{~g} . \%)$, very marked clubbing of the fingers, and prominent nodules over the elbows were also found. It was thought possible that an early subacute bacterial endocarditis was present, despite the fact that the patient was apyrexial, and a series of blood cultures gave the following results:-May 10: a few colonies of a haemolytic coagulase-negative Staph. albus; May 12: no growth; May 16 and 17: a heavy growth of a haemolytic coagulase-negative Staph. albus.

In vitro tests showed that the organisms isolated (presumably all the same strain) were sensitive to penicillin ; $1,000,000$ units of penicillin daily was given when the second positive culture was reported-this was continued for five weeks. The patient's condition improved dramatically with penicillin therapy. The haemoglobin rose to $11.9 \mathrm{~g} . \%$, her weight increased, and symptoms of tiredness and malaise disappeared. Nine blood cultures taken between May 25 and July 30 were sterile. She was discharged on August 20. 